\title{
Effects of antiviral therapy on post-hepatectomy HBV reactivation and liver function in HBV DNA-negative patients with HBV- related hepatocellular carcinoma
}

\author{
Wen-Feng Gong ${ }^{1,2, *}$, Jian-Hong Zhong ${ }^{1,2, *}$, Shi-Dong Lu $^{1,2}$, Xiao-Bo Wang ${ }^{1,2}$, Qiu- \\ Ming Zhang ${ }^{3}$, Liang Ma ${ }^{1,2}$, Zhi-Ming Zhang ${ }^{1,2}$, Bang-De Xiang ${ }^{1,2}$, Le-Qun $\mathrm{Li}^{1,2}$ \\ ${ }^{1}$ Hepatobiliary Surgery Department, Affiliated Tumor Hospital of Guangxi Medical University, Nanning 530021, China \\ ${ }^{2}$ Guangxi Liver Cancer Diagnosis and Treatment Engineering and Technology Research Center, Nanning 530021, China \\ ${ }^{3}$ General Medicine Department, The First People Hospital of Qinzhou, Qinzhou, 535000, China \\ *These authors contributed equally to this work and as co-first authors \\ Correspondence to: Le-Qun Li, email: xitongpingjia@163.com \\ Bang-De Xiang, email: xiangbangde@gmail.com
}

Keywords: hepatocellular carcinoma, hepatitis B virus, antiviral, reactivation, liver function

Received: November 30, 2016

Accepted: January 11, 2017

Published: January 21, 2017

\section{ABSTRACT}

The ability of antiviral therapy to reduce risk of post-hepatectomy hepatitis B virus (HBV) reactivation in patients negative for viral DNA is unclear. This prospective study involved 174 consecutive patients with hepatitis B virus related hepatocellular carcinoma who were negative for hepatitis $B$ virus DNA in serum and who underwent hepatic resection. Hepatitis $B$ virus reactivation occurred in $\mathbf{3 0}$ patients in the non-antiviral group $(27.8 \%)$ but in only 2 patients in the antiviral group $(3.0 \%$, $P<0.001)$. Based on multivariate analysis, risk of hepatitis $B$ virus reactivation was associated with minor hepatectomy and absence of antiviral therapy. Liver function indicators at one week after resection did not differ significantly between the two groups, or between patients who experienced hepatitis B virus reactivation or not. Nevertheless, alanine aminotransferase and albumin at 1 month after resection were significantly higher in the antiviral group than in the non-antiviral group, and they were significantly higher in patients who did not experience hepatitis $B$ virus reactivation than in those who did. Therefore, patients with hepatitis $B$ virus related hepatocellular carcinoma face substantial risk of hepatitis B virus reactivation after hepatectomy, even if they are negative for viral DNA at baseline. Antiviral therapy can reduce the risk of reactivation, helping improve liver function after surgery. (Clinicaltrials.gov registration number: NCT02829359).

\section{INTRODUCTION}

Hepatocellular carcinoma (HCC) is the fifth most common cancer worldwide and the third most common cause of cancer mortality [1,3]. In Asian countries, hepatitis B virus (HBV) infection has been identified as an important etiological factor in hepatocarcinogenesis. Patients with HBV-related HCC therefore require preor postoperative antiviral treatment, which can induce remission of active hepatitis, help maintain hepatic function, prevent HCC recurrence and increase the likelihood of successful treatment if the disease does recur [4].
Such postoperative antiviral therapy may not be enough. Numerous studies have shown that conformal radiotherapy [5-6], systemic chemotherapy [7-8], radiofrequency ablation [9] and transcatheter arterial chemoembolization (TACE) [10-11] can lead to HBV reactivation and hepatic dysfunction during treatment. Hepatectomy of patients with HBV-related HCC who are positive for HBV DNA in serum can lead to HBV reactivation during the perioperative period, and patients positive for HBV DNA or HBV surface antigen (HBsAg) may be at particularly high risk of reactivation $[7,9]$. HBV reactivation can degrade liver function [12], aggravateliver cirrhosis [13], increase the risk of HBV-related HCC 
recurrence [14], and increase the incidence and severity of potentially life-threatening complications [15]. For these reasons, official guidelines [16-19] recommend simultaneous comprehensive anti-tumor treatment and antiviral treatment for HCC patients positive for HBV DNA.

It is unclear whether antiviral therapy during the perioperative period can also benefit patients who have HBV-related HCC but who are negative for HBV DNA. The present study evaluated the incidence of post-hepatectomy HBV reactivation in such patients and explored the risk factors of reactivation. The influence of $\mathrm{HBV}$ reactivation on liver function recovery was also analyzed.

\section{RESULTS}

\section{Study population characteristics}

During the enrollment period, 1,684 potentially eligible patients were admitted for initial hepatectomy at our hospital between July 2012 and June 2016. Of these, 1489 were excluded because they were negative for serum HBsAg $(n=32)$, positive for HBV DNA $(n=1455)$ or positive for antibodies against hepatitis $\mathrm{C}$ virus $(n=2)$. A total of 195 patients who had HBV-related HCC and who were positive for serum HBsAg and negative for $\mathrm{HBV}$ DNA prior to hepatectomy were enrolled. After enrollment, 17 patients were excluded because they received TACE or other antitumor therapy before hepatectomy $(n=8)$, they had previously received antiviral therapy within one year of study enrollment $(n=7)$, or they had another cancer $(n=1)$ or autoimmune disease $(n=1)$. Another 4 patients were excluded when postoperative histopathology showed them to have intrahepatic cholangiocarcinoma. In the end, 66 patients were included in the antiviral group and 108 in the non-antiviral group (Figure 1).

The proportion of patients receiving minor hepatectomy was significantly higher in the antiviral group $(P=0.041)$, who also had a significantly lower mean albumin level than the non-antiviral group $(P=0.032)$. The two groups were similar across all other variables analyzed (all $P>0.05$; Table 1 ).

\section{HBV reactivation}

By 1-month follow-up, HBV reactivation had occurred in a significantly larger proportion of patients in the non-antiviral group [30/108, $(27.8 \%)]$ than in the antiviral group [2/64 (3.0\%), $P<0.001]$. Most reactivation events occurred soon after surgery: 8 patients experienced initial reactivation on postoperative day 1,16 patients on day 3 (including the two patients in the antiviral group), 5 patients on day 5, 2 patients on day 7, and 1 patient on day 9 . Patients who experienced reactivation were considered for antiviral therapy (Table 2).

Univariate analysis identified the following risk factors of perioperative $\mathrm{HBV}$ reactivation (all $P<0.05$;
Table 3): cirrhosis, low serum albumin, minor hepatectomy and absence of antiviral therapy. Multivariate analysis identified only two risk factors $(P<0.05$; Table 4$)$ : minor hepatectomy and absence of antiviral therapy.

\section{Effect of $\mathrm{HBV}$ reactivation on recovery of liver function}

At 1 week after hepatectomy, the antiviral and nonantiviral groups showed similar liver function in terms of alanine aminotransferase, total bilirubin, albumin, and prothrombin time (all $P>0.05$; Figure 2). However, alanine aminotransferase was significantly lower and albumin significantly higher in the antiviral group than in the non-antiviral group at 1 month after hepatectomy, indicating better liver function (both $P<0.05$; Figure 2). Stratifying patients according to whether they experienced HBV reactivation or not revealed no significant differences in alanine aminotransferase, total bilirubin, albumin, or prothrombin time at 1 week after surgery. At 1 month after hepatectomy, however, liver function was better in patients without HBV reactivation than in those who experienced it (Figure 3).

\section{DISCUSSION}

The major drug treatments against chronic HBV infection, interferon and nucleoside/nucleotide analogues, usually do not completely eliminate the virus [20]. Even with these treatments, some copies of HBV covalently closed circular DNA persist in infected hepatocytes [21]. As a result, immunosuppressive drug therapy and surgery can trigger genome amplification, leading in turn to HBV reactivation [19]. For patients with HBV-related HCC who are positive for HBV DNA, official guidelines recommend entecavir and tenofovir as first-line postoperative antiviral therapy to suppress viral replication and thereby help improve liver function, decrease tumor recurrence, and prolong overall survival [16-18]. The present study shows that perioperative antiviral therapy with entecavir can also improve prognosis of patients who are negative for HBV DNA.

To our knowledge, this is the first systematic study to explore the incidence of HBV reactivation after hepatectomy in HCC patients who are positive for serum HBsAg but negative for HBV DNA at baseline. Our results show a 9-fold reduction in the rate of HBV reactivation within 1 month of hepatectomy when antiviral therapy is begun a few days before surgery and continued for at least 1 month afterwards.

Our results indicate that $\mathrm{HBV}$ reactivation is a serious concern even for HCC patients who are negative for viral DNA at baseline. This extends and complements an already extensive literature documenting the substantial risk of reactivation in patients positive for viral DNA. In one study of $55 \mathrm{HCC}$ patients with high levels of 
Table 1: Baseline characteristics of included patients

\begin{tabular}{|c|c|c|c|}
\hline Variable & $\begin{array}{c}\text { Antiviral group } \\
\quad(n=66)\end{array}$ & $\begin{array}{c}\text { Non-antiviral group } \\
(n=108)\end{array}$ & $\boldsymbol{P}$ \\
\hline $\operatorname{Sex}(\mathrm{M} / \mathrm{F})$ & $58 / 8$ & $92 / 16$ & 0.617 \\
\hline Age (yr) & $49.97 \pm 9.71$ & $49.67 \pm 12.22$ & 0.904 \\
\hline BCLC stage (A/B/C) & $42 / 12 / 12$ & $60 / 20 / 28$ & 0.466 \\
\hline Tumor number $(<3 / \geq 3)$ & $56 / 10$ & $98 / 10$ & 0.237 \\
\hline Tumor size $(>5 / \leq 5 \mathrm{~cm})$ & $34 / 32$ & $62 / 46$ & 0.448 \\
\hline Preoperative tumor rupture (yes/no) & $4 / 62$ & $6 / 102$ & 1.000 \\
\hline Blood loss (mL) & $448.42 \pm 303.73$ & $459.26 \pm 219.74$ & 0.848 \\
\hline Blood transfusion (yes/no) & $2 / 64$ & $8 / 100$ & 0.322 \\
\hline Operative time (min) & $202.58 \pm 69.41$ & $195.50 \pm 53.65$ & 0.595 \\
\hline Tumor capsule (complete/absent + incomplete) & $44 / 22$ & $64 / 44$ & 0.329 \\
\hline Anatomical hepatectomy (yes/no) & $12 / 54$ & $34 / 74$ & 0.054 \\
\hline Inflow blood occlusion time (min) & $28.03 \pm 25.40$ & $24.98 \pm 38.88$ & 0.690 \\
\hline Liver cirrhosis (present/absent) & $54 / 12$ & $87 / 21$ & 0.837 \\
\hline Alpha fetoprotein $\geq 400 \mathrm{ng} / \mathrm{mL}$ & 32 & 50 & 0.779 \\
\hline Prothrombin time (s) & $12.82 \pm 1.29$ & $12.77 \pm 1.41$ & 0.857 \\
\hline Total bilirubin $(\mu \mathrm{mol} / \mathrm{L})$ & $10.50 \pm 3.85$ & $20.17 \pm 5.37$ & 0.303 \\
\hline $\operatorname{Albumin}(\mathrm{g} / \mathrm{L})$ & $40.24 \pm 5.19$ & $42.57 \pm 4.61$ & 0.032 \\
\hline Alanine aminotransferase (IU/L) & $20.97 \pm 15.08$ & $22.39 \pm 17.61$ & 0.617 \\
\hline Ascites (present/absent) & $2 / 64$ & $2 / 106$ & 0.635 \\
\hline Types of hepatectomy (major/minor) & $4 / 62$ & $18 / 90$ & 0.041 \\
\hline Hepatitis B virus Pre-S1 antigen (positive/negative) & $46 / 20$ & $60 / 48$ & 0.064 \\
\hline
\end{tabular}

BCLC, Barcelona Clinic Liver Cancer.

HBV DNA ( $\geq 7 \mathrm{mEq} / \mathrm{ml}$ ) at baseline, post-hepatectomy reactivation occurred in $28 \%$ and hepatitis in $24 \%$ [22]. Another study of HCC patients with high HBV DNA levels $\left(\geq 2.0 \times 10^{3} \mathrm{IU} / \mathrm{ml}\right)$ reported rates of $\mathrm{HBV}$ reactivation during the perioperative period of $31.8 \%(14 / 44)$ in the non-antiviral group and $2.5 \%(1 / 40)$ in the antiviral group [23]. HBV reactivation rates also appear to be relatively high for patients with lower levels of viral DNA. In a study of HCC patients with preoperative HBV DNA levels $<2.0$ $\times 10^{2} \mathrm{IU} / \mathrm{ml}$, reactivation occurred after hepatectomy in $21.1 \%$ without antiviral therapy [7]. In a study of patients with preoperative $\mathrm{HBV}$ DNA $<2000 \mathrm{IU} / \mathrm{ml}$, reactivation occurred after resection in $19.1 \%$ [12]. This last study identified HBV DNA levels > $200 \mathrm{IU} / \mathrm{ml}$ and HBV reactivation as independent risk factors of poor diseasefree and overall survival. The present results with HBV DNA-negative HCC patients, together with the existing literature on DNA-positive patients, strongly suggest that all HBsAg-positive HCC patients face substantial risk of postoperative reactivation. Thus, it may be beneficial to routinely administer prophylactic antiviral treatment to such patients before and immediately after hepatectomy.
How HBV reactivation occurs remains unclear. Hepatectomy may induce immunosuppression and thereby lead to HBV replication [24-26]. Subsequent recovery of immune function results in rapid destruction of infected hepatocytes, causing postoperative hepatitis and acute hepatic failure. In addition, HBV can integrate into liver cells and persist for long periods, protected from immune monitoring. As liver cells regenerate following hepatectomy, HBV can infect these cells because of its strong hepatotropism, causing viral load to increase.

In our cohort, minor hepatectomy was a risk factor of $\mathrm{HBV}$ reactivation. How this procedure can reactivate viral replication is poorly understood. We attribute this association to the issue of residual viral load. Major hepatectomy, in theory, eliminates a large amount of HBV load, and reactivation in the remnant liver should be difficult to detect since relatively little hepatic tissue remains and the cells regenerate slowly. In minor hepatectomy, however, remnant liver volume is large and so is the residual viral load. The residual liver tissue can regenerate fairly quickly, and the abundant HBV can infect the new tissue relatively easily. Thus, it stands to 


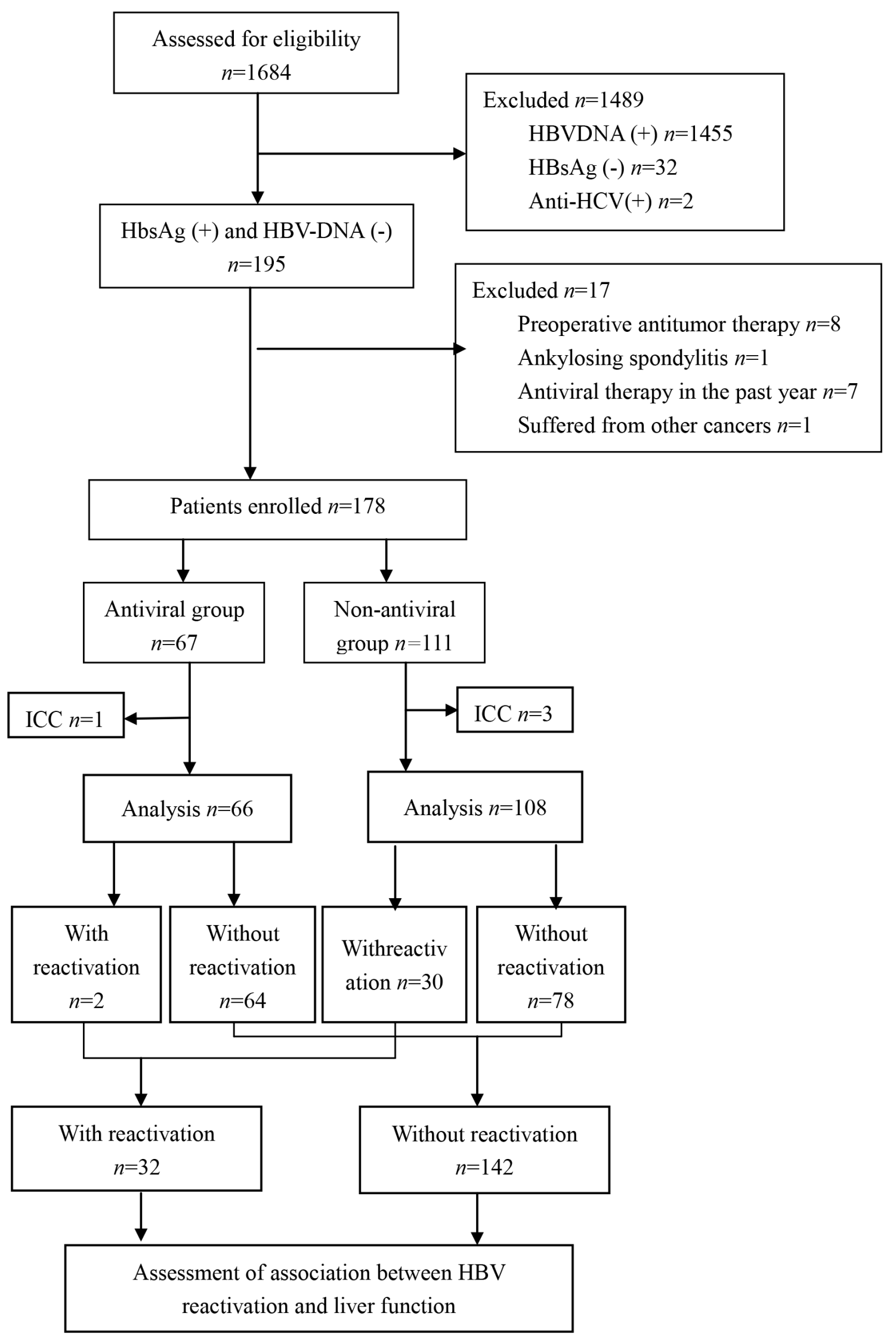

Figure 1: Patient enrollment and assessment. 
Table 2: HBV DNA levels in patients in the antiviral and non-antiviral groups who experienced HBV reactivation within 1 month of hepatectomy.

\begin{tabular}{|c|c|c|c|c|c|c|c|}
\hline $\begin{array}{c}\text { Day } \\
\text { Patient }\end{array}$ & D0 & D1 & D3 & D5 & D7 & D9 & D30 \\
\hline 1 & $\geq$ & 872 & 826 & 893 & 840 & 795 & 780 \\
\hline 2 & $\geq$ & 500 & 771 & 795 & 780 & 764 & 750 \\
\hline 3 & $\geq$ & 1012 & 1025 & 1109 & 1018 & 997 & 1007 \\
\hline 4 & $\geq$ & 695 & 708 & 713 & 677 & 701 & 700 \\
\hline 5 & $\geq$ & 598 & 631 & 621 & 587 & 600 & 624 \\
\hline 6 & $\geq$ & 725 & 713 & 751 & 720 & 704 & 700 \\
\hline 7 & $\geq$ & 818 & 843 & 819 & 800 & 792 & 805 \\
\hline 8 & $\geq$ & 796 & 826 & 819 & 804 & 788 & 827 \\
\hline 9 & $\geq$ & $\geq$ & 912 & 897 & 901 & 850 & 829 \\
\hline 10 & $\geq$ & $\geq$ & 738 & 725 & 771 & 698 & 708 \\
\hline 11 & $\geq$ & $\geq$ & 852 & 842 & 880 & 799 & 813 \\
\hline 12 & $\geq$ & $\geq$ & 924 & 854 & 869 & 941 & 850 \\
\hline 13 & $\geq$ & $\geq$ & 713 & 402 & 750 & 692 & 700 \\
\hline 14 & $\geq$ & $\geq$ & 816 & 800 & 806 & 794 & 750 \\
\hline 15 & $\geq$ & $\geq$ & 903 & 885 & 897 & 904 & 916 \\
\hline 16 & $\geq$ & $\geq$ & 759 & 746 & 782 & 729 & 741 \\
\hline 17 & $\geq$ & $\geq$ & 685 & 653 & 674 & 627 & 608 \\
\hline 18 & $\geq$ & $\geq$ & 599 & 586 & 607 & 581 & 620 \\
\hline 19 & $\geq$ & $\geq$ & 619 & 627 & 641 & 608 & 574 \\
\hline 20 & $\geq$ & $\geq$ & 598 & 571 & 588 & 559 & 607 \\
\hline 21 & $\geq$ & $\geq$ & 667 & 695 & 684 & 673 & 650 \\
\hline 22 & $\geq$ & $\geq$ & 652 & 677 & 692 & 628 & 672 \\
\hline 23 & $\geq$ & $\geq$ & 954 & 928 & 973 & 900 & 929 \\
\hline 24 & $\geq$ & $\geq$ & 856 & 849 & 872 & 827 & 867 \\
\hline 25 & $\geq$ & $\geq$ & $\geq$ & 873 & 859 & 894 & 807 \\
\hline 26 & $\geq$ & $\geq$ & $\geq$ & 691 & 685 & 726 & 708 \\
\hline 27 & $\geq$ & $\geq$ & $\geq$ & 655 & 639 & 675 & 649 \\
\hline 28 & $\geq$ & $\geq$ & $\geq$ & 863 & 855 & 849 & 895 \\
\hline 29 & $\geq$ & $\geq$ & $\geq$ & 529 & 537 & 542 & 518 \\
\hline 30 & $\geq$ & $\geq$ & $\geq$ & $\geq$ & 639 & 622 & 640 \\
\hline $31^{*}$ & $\geq$ & $\geq$ & $\geq$ & $\geq$ & 593 & 607 & 612 \\
\hline $32^{*}$ & $\geq$ & $\geq$ & $\geq$ & $\geq$ & $\geq$ & 526 & 538 \\
\hline
\end{tabular}

${ }^{*}$ Patients in the antiviral group who experienced HBV reactivation. D0, preoperative HBV DNA level (baseline); D1, D3, D5, D7, D9, D30 etc., postoperative HBV DNA levels; $\geq$, HBV DNA level < $500 \mathrm{IU} / \mathrm{ml}$.

reason that minor hepatectomy leads to greater risk of postoperative $\mathrm{HBV}$ reactivation than the corresponding major procedure. We did not observe that liver cirrhosis, albumin $\leq 35 \mathrm{~g} / \mathrm{L}$ or other clinical factors correlated significantly with HBV reactivation after hepatectomy.

Our results suggest that although the use of prophylactic antiviral therapy and occurrence of HBV reactivation do not appear to significantly improve liver function within 1 week after hepatectomy, they can influence function at 1 month. This may reflect the fact that liver function soon after hepatectomy reflects primarily damage due to the surgery itself, whereas damage over longer periods reflects the continuous processes that give rise to reactivation. Our results are consistent with previous reports that antiviral therapy can reduce HBV reactivation-induced liver damage, improve liver function, promote hepatocyte regeneration and increase the volume of residual liver after hepatectomy [27-29]. 
Table 3: Univariate analysis to identify factors related to perioperative $\mathrm{HBV}$ reactivation

\begin{tabular}{|c|c|c|c|}
\hline Variable & $\begin{array}{l}\text { HBV reactivation } \\
\quad(n=32)\end{array}$ & $\begin{array}{l}\text { No HBV reactivation } \\
\qquad(n=142)\end{array}$ & $\boldsymbol{P}$ \\
\hline $\operatorname{Sex}(\mathrm{M} / \mathrm{F})$ & $28 / 4$ & $122 / 20$ & 1.000 \\
\hline Age (yr) & $50.25 \pm 11.01$ & $49.68 \pm 11.41$ & 0.855 \\
\hline BCLC-stage $(\mathrm{A} / \mathrm{B} / \mathrm{C})$ & $16 / 10 / 6$ & $86 / 22 / 34$ & 0.115 \\
\hline Tumor numbers $(<3 / \geq 3)$ & $28 / 4$ & $126 / 16$ & 0.766 \\
\hline Tumor size $(>5 / \leq 5 \mathrm{~cm})$ & $16 / 16$ & $80 / 62$ & 0.515 \\
\hline Tumor size $(\mathrm{cm})$ & $5.83 \pm 2.60$ & $6.94 \pm 4.08$ & 0.299 \\
\hline Preoperative tumor rupture (yes/no) & $2 / 30$ & $8 / 134$ & 1.000 \\
\hline Blood loss (mL) & $323.13 \pm 238.38$ & $362.37 \pm 257.49$ & 0.578 \\
\hline Blood transfusion (yes/no) & $3 / 29$ & $7 / 135$ & 0.394 \\
\hline Operative time(min) & $194.38 \pm 53.26$ & $199.04 \pm 61.52$ & 0.780 \\
\hline Tumor capsule (complete/ absent + incomplete) & $20 / 12$ & $88 / 54$ & 0.956 \\
\hline Anatomical hepatectomy (yes/no) & $8 / 24$ & $38 / 104$ & 0.838 \\
\hline Inflow blood occlusion time (min) & $21.00 \pm 14.72$ & $25.04 \pm 23.61$ & 0.514 \\
\hline Liver cirrhosis (present/absent) & $30 / 2$ & $111 / 31$ & 0.042 \\
\hline Alpha fetoprotein $\geq 400 \mathrm{ng} / \mathrm{mL}$ & 12 & 70 & 0.227 \\
\hline Prothrombin time $(\mathrm{s})$ & $12.95 \pm 1.95$ & $12.75 \pm 1.20$ & 0.599 \\
\hline Total bilirubin $(\mu \mathrm{mol} / \mathrm{L})$ & $13.98 \pm 6.43$ & $17.08 \pm 46.70$ & 0.792 \\
\hline Albumin $(\mathrm{g} / \mathrm{L})$ & $44.68 \pm 2.12$ & $41.01 \pm 5.15$ & 0.007 \\
\hline Alanine aminotransferase (IU/L) & $34.38 \pm 14.35$ & $33.27 \pm 23.16$ & 0.855 \\
\hline Ascites (present/absent) & $1 / 31$ & $3 / 139$ & 0.560 \\
\hline Types of hepatectomy (major/minor) & $24 / 8$ & $128 / 14$ & 0.020 \\
\hline $\begin{array}{l}\text { Hepatitis B virus Pre-S1 antigen (positive/ } \\
\text { negative) }\end{array}$ & $20 / 12$ & $86 / 56$ & 0.839 \\
\hline Antiviral therapy (yes/no) & $2 / 30$ & $64 / 78$ & $<0.001$ \\
\hline
\end{tabular}

BCLC, Barcelona Clinic Liver Cancer.

Since our study focused on the perioperative period, we did not conduct longer follow-up. Future studies should be repeated with longer follow-up to examine the prognosis of HBV DNA-negative patients with HBV-related HCC who receive prophylactic antiviral therapy.

In addition to its short follow-up, our study has several other limitations. During the first week, we did not assay liver function using the ascites test, even though this is one of the indices for Child-Pugh assessment of liver function. We did not use this test because the presence of ascites need not indicate poor liver function; it can also occur as a result of inflammation, lymphatic blockage, and changes in plasma osmotic pressure [30]. In addition, our study was based on a small sample, and our detection limit of $500 \mathrm{IU} / \mathrm{ml}$ of HBV DNA may not be sufficiently sensitive to detect low levels of viral replication. We did not genotype the HBV strains in our patients, leaving open the question of whether genotype influences risk of $\mathrm{HBV}$ reactivation. Last, patients were not randomized allocated. This study has the inherent defect of comparing management and surgery by different teams of surgeons, thus introducing possible biases into this study.

While our cohort contained only patients undergoing initial hepatectomy, $\mathrm{HCC}$ recurs in up to $75 \%$ of patients by 5 years after initial surgery [31]. Such patients must then undergo TACE, radiofrequency ablation, anhydrous alcohol injection, three-dimensional conformal radiotherapy, some other comprehensive multimodal treatment or even repeat surgery [32-33]. All these treatments can trigger HBV reactivation and further compromise liver function. Therefore our work demonstrating the clinical benefit of prophylactic antiviral therapy is likely to be relevant for patients with initial and recurrent HCC. In particular, our results support the use of perioperative antiviral therapy in $\mathrm{HCC}$ patients who are positive for HBsAg and negative for HBV DNA. Our results should be confirmed and extended in larger studies with longer follow-up. 
Table 4: Multivariate analysis with logistic regression to identify factors related to perioperative HBV reactivation

\begin{tabular}{|l|c|c|c|}
\hline \multicolumn{1}{c}{ Variable } & Hazard ratio & 95\% confidence interval & 0.066 \\
\hline Liver cirrhosis (present) & 5.804 & $0.888-37.945$ & 0.501 \\
\hline Albumin $\leq 35 \mathrm{~g} / \mathrm{L}$ & 0.452 & $0.045-4.569$ & 0.021 \\
\hline Minor hepatectomy $(\leq 3$ liver segments) & 4.695 & $1.257-17.537$ & 0.006 \\
\hline Noantiviral therapy & 8.164 & $1.831-36.397$ & \\
\hline
\end{tabular}
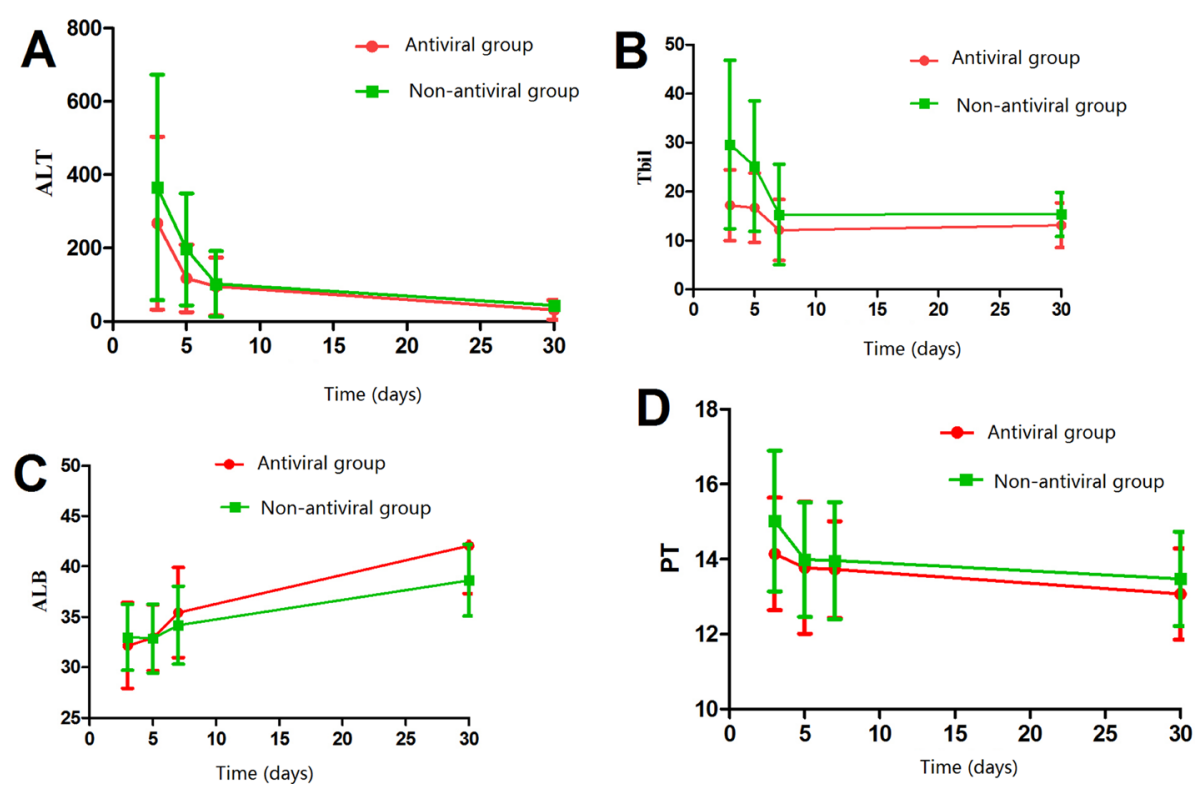

Figure 2: Comparison of liver function between patients with or without perioperative antiviral therapy.
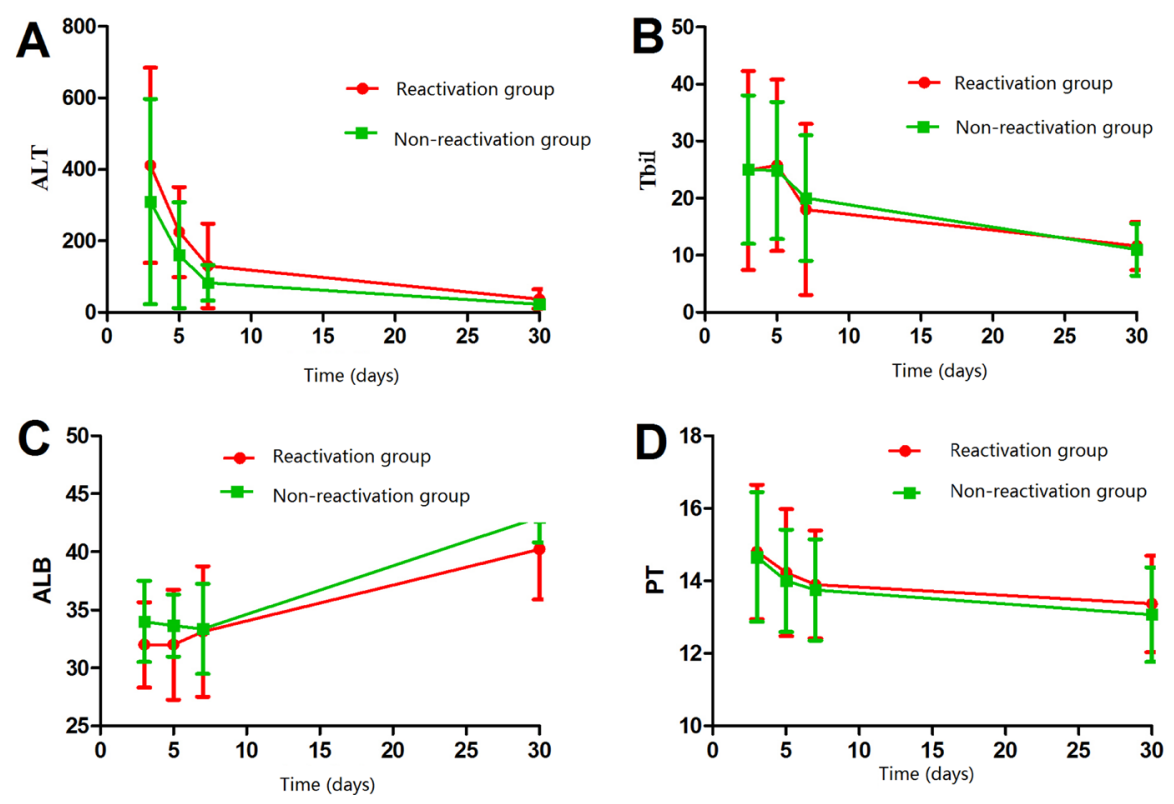

Figure 3: Comparison of liver function between patients who experienced post-hepatectomy HBV reactivation or not. 


\section{MATERIALS AND METHODS}

\section{Consent and ethical approval statement}

Written informed consent was obtained from the patients in this study prior to their undergoing hepatectomy. All procedures in this study were in accordance with the rules of the Research Ethics Committee of the Affiliated Tumor Hospital of Guangxi Medical University and with the 1964 Helsinki Declaration and its amendments.

\section{Patients}

This prospective study involved 174 consecutive patients with HBV-related HCC who underwent hepatectomy between July 2012 and June 2016 at the Affiliated Tumor Hospital of Guangxi Medical University. All patients were assayed for HBsAg and its antibody, hepatitis B e antigen and its antibody, antibody to HBV core antigen, HBV Pre-S1, antibody to hepatitis C virus, HBV DNA, serum alanine aminotransferase, serum albumin, prealbumin, total bilirubin, prothrombin time, and alpha-fetoprotein. Patients also underwent computed tomography of the liver one week before surgery. The trial is retrospectively registered (July 11, 2016) at Clinicaltrials.gov (NCT02829359).

Patients were included in the present study if they satisfied all the following inclusion criteria: (a) they underwent initial hepatectomy, (b) they were positive for serum HBsAg before surgery, (c) they were negative for serum HBV DNA (< $500 \mathrm{IU} / \mathrm{ml})$; (d) their serum alanine aminotransferase was within the normal range, (e) they had Child-Pugh A liver function, (f) their HCC was confirmed by histopathology, and (g) they received either entecavir antiviral therapy or no antiviral therapy before (not exceeding 7 days) and after hepatectomy.

Patients were excluded from this trial if they met any of the following criteria: (a) they received TACE or other anti-tumor treatments prior to hepatectomy; (b) they had previously received antiviral treatment within 12 months of entering the study; or (c) they had autoimmune disease, malignant tumors in other organs, or other severe disease.

Levels of HBV DNA in serum were quantified using real-time polymerase chain reaction coupled to a fluorescence assay in a commercial hepatitis detection kit (DaAn Gene, Guangzhou, China). The manufacturerspecified lower limit of quantification was $500 \mathrm{IU} / \mathrm{ml}$. HBV reactivation was defined as a shift in HBV DNA levels from being undetectable at baseline to being detectable. Liver function was compared before and after hepatectomy using the indices alanine aminotransferase, total bilirubin, albumin, and prothrombin time.

\section{Patient allocation and perioperative management}

Our two Hepatobiliary Surgery Departments are divided into several medical teams by the senior doctors.
In three medical teams, patients who met the inclusion criteria would receive entecavir $(0.5 \mathrm{mg} / \mathrm{d}$; Zhengda Tianqing, Lianyungang, China) starting 3 days before hepatectomy and for at least 1 month afterwards. These patients were assigned as the antiviral group. In the other medical teams, patients did not receive any antiviral therapy and they would be assigned as the non-antiviral group. Patients in the non-antiviral group who experienced HBV reactivation were considered for entecavir therapy after enrollment in the study, as per standard practices [16]. None of the patients in our study received immunological therapy during the perioperative period (defined as during hepatectomy or up to 1 month afterwards).

Hepatectomy was performed as described [34-35]. Perioperative data were recorded about type of hepatectomy, blood loss volume, tumor size, tumor capsule, duration of porta hepatis clamping, and duration of surgery. Data were also recorded about transfusion of red cells and blood plasma and about infusion of human blood albumin during and after hepatectomy. Indications for transfusions and infusions were as described [36-37]. The duration of inflow blood occlusion was defined to be the duration of porta hepatis clamping. Major hepatectomy was defined as the resection of three or more Couinaud segments; minor hepactectomy, as the resection of fewer than three segments.

On postoperative days 1-7, all patients received drug therapy [Magnesium Isoglycyrrhizinate for Injection, 150 $\mathrm{mg} / \mathrm{d}$, Zhengda Tianqing, Lianyungang, China; Ademetionine 1,4-Butanedisulfonate for Injection, $1000 \mathrm{mg} / \mathrm{d}$, Abbott S.P.A, Via Pontina Km 5204010 Campoverde (Aprilia) LT, Italy] to protect liver function and lower transaminase levels. HBVDNA levels, liver function, and blood clotting function were assayed on days $1,3,5,7,9$ and 30 after hepatectomy. Criteria for hospital discharge included stability of vital signs with no fever, ability to tolerate solid food without vomiting, absence of other postoperative complications, control of postoperative pain, and ability to function at home independently or with home care [38].

\section{Statistical analysis}

Continuous data were reported as mean and standard deviation and compared between patient groups using the independent-samples $t$ test. Categorical data were reported as percentages and compared between patient groups using the chi-squared or Fisher's exact tests as appropriate. Multivariate analysis with logistic regression was used to identify risk factors of HBV reactivation. The threshold of significance was defined as two-tailed $P<0.05$. Data were analyzed using SPSS 17.0 (IBM, USA).

\section{CONCLUSIONS}

We provide evidence that liver resection can trigger $\mathrm{HBV}$ reactivation during the perioperative period in patients who have HBV-related HCC and who are negative for 
serum HBV DNA. Our results further suggest that the risk of reactivation is significantly lower when such patients are given perioperative prophylactic antiviral therapy. Reducing the risk of reactivation helps improve postoperative liver function. However, the long-term efficacy of entecavir for such patients was unknown. Besides, patient without liver cirrhosis was not analyzed specifically. Therefore, our conclusions remain highly preliminary and must be verified in much larger studies with longer follow-up that take into account these limitations.

\section{ACKNOWLEDGMENTS}

The authors express their sincere gratitude to the patients and staff of the Hepatobiliary Surgery Department of the Tumor Hospital of Guangxi Medical University for their valuable efforts. These authors (W.-F.G and J.-H.Z) thanks Ming-Hua Zheng, $\mathrm{PhD}$, and Bhavesh.K Ahir, $\mathrm{PhD}$ for their kindly help of revision and suggestion of the manuscript.

\section{CONFLICTS OF INTEREST}

The authors have no financial or personal conflicts of interest to disclose.

\section{FUNDING}

This work was supported by the National Science and Technology Major Special Project of the Ministry of Science and Technology of China (2012ZX10002010001009), the Guangxi University of Science and Technology Research Projects (KY2015LX056), the Self-Raised Scientific Research Fund of the Ministry of Health of Guangxi Province (Z2015601， Z2016512， Z2015621， GZZC15-34, Z2014241), the Scientific Research Fund of the Ministry of Health of Guangxi Province (S201417-02), the Youth Science Foundation of Guangxi Medical University (GXMUYSF201517) and the Guangxi Science and Technology Development Projects (14124003-4).

\section{Authors' contributions}

W.-F.G and B.-D.X conceived and designed the study. S.-D.L, X.-B.W, Q.-M.Z, W.-F.G, Z.-M.Z, L.Q.L, and J.-H.Z collected data. W.-F.G, J.-H.Z and L.M interpreted the data and performed statistical analyses. W.F.G and J.-H.Z drafted the article. All authors reviewed and approved the final manuscript.

\section{REFERENCES}

1. Miller KD, Siegel RL, Lin CC, Mariotto AB, Kramer JL, Rowland JH, Stein KD, Alteri R, Jemal A. Cancer treatment and survivorship statistics, 2016. CA Cancer J Clin. 2016; 66:271-289.
2. Siegel RL, Miller KD, Jemal A. Cancer statistics, 2016. CA Cancer J Clin. 2016; 66:7-30.

3. Zhong JH, You XM, Ma L, Xiang BD, Wu FX, Peng NF, Gong WF, Li LQ. Tumor stage and primary treatment selection among patients with hepatocellular carcinoma from 2003 to 2013. Chin J of Oncol Prev and Treat. 2015; 7:403-407.

4. Kubo S, Takemura S, Sakata C, Urata Y, Uenishi T. Adjuvant therapy after curative resection for hepatocellular carcinoma associated with hepatitis virus. Liver Cancer. $2013 ; 2: 40-46$.

5. Huang W, Zhang W, Fan M, Lu Y, Zhang J, Li H, Li B. Risk factors for hepatitis $\mathrm{B}$ virus reactivation after conformal radiotherapy in patients with hepatocellular carcinoma. Cancer Sci. 2014; 105:697-703.

6. Kim JH, Park JW, Kim TH, Koh DW, Lee WJ, Kim CM. Hepatitis B virus reactivation after three-dimensional conformal radiotherapy in patients with hepatitis B virusrelated hepatocellular carcinoma. Int J Radiat Oncol Biol Phys. 2007; 69:813-819.

7. Huang L, Li J, Lau WY, Yan J, Zhou F, Liu C, Zhang X, Shen J, Wu M, Yan Y. Perioperative reactivation of hepatitis B virus replication in patients undergoing partial hepatectomy for hepatocellular carcinoma. J Gastroenterol Hepatol. 2012; 27:158-164.

8. Yeo W, Lam KC, Zee B, Chan PS, Mo FK, Ho WM, Wong WL, Leung TW, Chan AT, Ma B, Mok TS, Johnson PJ. Hepatitis B reactivation in patients with hepatocellular carcinoma undergoing systemic chemotherapy. Ann Oncol. 2004; 15:1661-1666.

9. Dan JQ, Zhang YJ, Huang JT, Chen MS, Gao HJ, Peng ZW, Xu L, Lau WY. Hepatitis B virus reactivation after radiofrequency ablation or hepatic resection for $\mathrm{HBV}$ related small hepatocellular carcinoma: a retrospective study. Eur J Surg Oncol. 2013; 39:865-872.

10. Lao XM, Luo G, Ye LT, Luo C, Shi M, Wang D, Guo R, Chen M, Li S, Lin X, Yuan Y. Effects of antiviral therapy on hepatitis $\mathrm{B}$ virus reactivation and liver function after resection or chemoembolization for hepatocellular carcinoma. Liver Int. 2013; 33:595-604.

11. Jang JW, Choi JY, Bae SH, Yoon SK, Chang UI, Kim CW, Cho SH, Han JY, Lee YS. A randomized controlled study of preemptive lamivudine in patients receiving transarterial chemo-lipiodolization. Hepatology. 2006; 43:233-240.

12. Huang G, Lai EC, Lau WY, Zhou WP, Shen F, Pan ZY, $\mathrm{Fu} \mathrm{SY}, \mathrm{Wu}$ MC. Posthepatectomy HBV reactivation in hepatitis B-related hepatocellular carcinoma influences postoperative survival in patients with preoperative low HBV-DNA levels. Ann Surg. 2013; 257:490-505.

13. Wong GL, Chan HL, Mak CW, Lee SK, Ip ZM, Lam AT, Iu HW, Leung JM, Lai JW, Lo AO, Chan HY, Wong VW. Entecavir treatment reduces hepatic events and deaths in chronic hepatitis B patients with liver cirrhosis. Hepatology. 2013; 58:1537-1547.

14. Chan SL, Wong VW, Qin S, Chan HL. Infection and Cancer: The Case of Hepatitis B. J Clin Oncol. 2016; 34:83-90. 
15. Chen G, Lin W, Shen F, Iloeje UH, London WT, Evans AA. Past HBV viral load as predictor of mortality and morbidity from HCC and chronic liver disease in a prospective study. Am J Gastroenterol. 2006; 101:1797-1803.

16. European Association For The Study Of The Liver. EASL clinical practice guidelines: Management of chronic hepatitis B virus infection. J Hepatol. 2012; 57:167-185.

17. Liaw YF, Kao JH, Piratvisuth T, Chan HL, Chien RN, Liu CJ, Gane E, Locarnini S, Lim SG, Han KH, Amarapurkar D, Cooksley G, Jafri W, et al. Asian-Pacific consensus statement on the management of chronic hepatitis B: a 2012 update. Hepatol Int. 2012; 6:531-561.

18. Lok AS, McMahon BJ. Chronic hepatitis B: update 2009. Hepatology. 2009; 50:661-662.

19. Perrillo RP, Gish R, Falck-Ytter YT. American Gastroenterological Association Institute technical review on prevention and treatment of hepatitis B virus reactivation during immunosuppressive drug therapy. Gastroenterology. 2015; 148:221-244 e223.

20. Zhong JH, Ke Y, Zhu SL, Wang L, Luo CP, Gong WF, You XM, Ma L, Xiang BD and Li LQ. Adefovir dipivoxir is less expensive than lamivudine and associated with similar prognosis in patients with hepatitis B virus-related hepatocellular carcinoma after radical resection. Onco Targets Ther. 2016; 9:6897-6907.

21. Zhang E, Kosinska A, Lu M, Yan H, Roggendorf M. Current status of immunomodulatory therapy in chronic hepatitis B, fifty years after discovery of the virus: Search for the "magic bullet" to kill cccDNA. Antiviral Res. 2015; 123:193-203.

22. Kubo S, Nishiguchi S, Hamba H, Hirohashi K, Tanaka H, Shuto T, Kinoshita H, Kuroki T. Reactivation of viral replication after liver resection in patients infected with hepatitis B virus. Ann Surg. 2001; 233:139-145.

23. Huang L, Li J, Yan J, Sun J, Zhang X, Wu M,Yan Y. Antiviral therapy decreases viral reactivation in patients with hepatitis B virus-related hepatocellular carcinoma undergoing hepatectomy: a randomized controlled trial. J Viral Hepat. 2013; 20:336-342.

24. Zhong JH, Ma L, Li LQ. Postoperative Antiviral Therapy With Nucleos(t)ide Analogs in Patients With Hepatitis B Virus-related Hepatocellular Carcinoma. Ann Surg. 2015:[Epub ahead of print].

25. Zhong JH. Nucleos(t)ide analogue therapy for HBVrelated HCC after hepatic resection: clinical benefits and unanswered questions. Tumour Biol. 2014; 35:12779-12784.

26. Xie ZB, Zhu SL, Peng YC, Chen J, Wang XB, Ma L, Bai T, Xiang BD, Li LQ, Zhong JH. Postoperative hepatitis B virus reactivation and surgery-induced immunosuppression in patients with hepatitis B-related hepatocellular carcinoma. J Surg Oncol. 2015; 112:634-642.

27. Kuzuya T, Katano Y, Kumada T, Toyoda H, Nakano I, Hirooka Y, Itoh A, Ishigami M, Hayashi K, Honda T, Goto H. Efficacy of antiviral therapy with lamivudine after initial treatment for hepatitis B virus-related hepatocellular carcinoma. J Gastroenterol Hepatol. 2007; 22:1929-1935.
28. Piao CY, Fujioka S, Iwasaki Y, Fujio K, Kaneyoshi T, Araki Y, Hashimoto K, Senoh T, Terada R, Nishida T, Kobashi H, Sakaguchi K, Shiratori Y. Lamivudine treatment in patients with HBV-related hepatocellular carcinoma-using an untreated, matched control cohort. Acta Med Okayama. 2005; 59:217-224.

29. Li N, Lai EC, Shi J, Guo WX, Xue J, Huang B, Lau WY, Wu MC, Cheng SQ. A comparative study of antiviral therapy after resection of hepatocellular carcinoma in the immune-active phase of hepatitis B virus infection. Ann Surg Oncol. 2010; 17:179-185.

30. Deng L, Qin HG, Yang C, Zhong JH. Possible associations between ascites and vascular invasion in patients with hepatocellular carcinoma. Tumour Biol. 2015; 36:4933-4934.

31. Zhong JH, Rodriguez AC, Ke Y, Wang YY, Wang L, Li LQ. Hepatic resection as a safe and effective treatment for hepatocellular carcinoma involving a single large tumor, multiple tumors, or macrovascular invasion. Medicine (Baltimore). 2015; 94:e396.

32. Zhong JH, Ma L, Li LQ. Postoperative therapy options for hepatocellular carcinoma. Scand J Gastroenterol. 2014; 49:649-661.

33. Zhong JH, Li LQ, Wu LC. Lamivudine with or without adefovir dipivoxil for postoperative hepatocellular carcinoma. Cochrane Database Syst Rev. 2011:CD008713.

34. Zhong JH, Xiang BD, Gong WF, Ke Y, Mo QG, Ma L, Liu X, Li LQ. Comparison of long-term survival of patients with BCLC stage B hepatocellular carcinoma after liver resection or transarterial chemoembolization. PLoS One. 2013; 8:e68193.

35. Zhong JH, Ke Y, Gong WF, Xiang BD, Ma L, Ye XP, Peng T, Xie GS, Li LQ. Hepatic resection associated with good survival for selected patients with intermediate and advanced-stage hepatocellular carcinoma. Ann Surg. 2014; 260:329-340.

36. Yang T, Lu JH, Lau WY, Zhang TY, Zhang H, Shen YN, Alshebeeb K, Wu MC, Schwartz M, Shen F. Perioperative blood transfusion does not influence recurrence-free and overall survivals after curative resection for hepatocellular carcinoma: A Propensity Score Matching Analysis. J Hepatol. 2016; 64:583-593.

37. Zhong JH, Xiang BD, Li LQ. Blood transfusion and postoperative complications: a cautionary comment. Transl Gastroenterol Hepatol. 2016; 1:57.

38. You XM, Mo XS, Ma L, Zhong JH, Qin HG, Lu Z, Xiang BD, Wu FX, Zhao XH, Tang J, Pang YH, Chen J, Li LQ. Randomized Clinical Trial Comparing Efficacy of Simo Decoction and Acupuncture or Chewing Gum Alone on Postoperative Ileus in Patients With Hepatocellular Carcinoma After Hepatectomy. Medicine (Baltimore). 2015; 94:e1968. 